\title{
Repeated writing facilitates children's memory for pseudocharacters and foreign letters
}

\author{
MAKIKO NAKA \\ Chiba University, Chiba, Japan
}

\begin{abstract}
In a logographic language culture, repeated (hand)writing is a common memory strategy for learning letters and Chinese characters. The purpose of this paper is to determine whether this strategy facilitates children's memory for pseudologographic characters and foreign letters. It also explores which aspect of writing, the use of stroke orders or the writing action itself, is responsible for the effect. First, third, and fifth grade Japanese children participated in the study. Results showed that, for all the subjects, characters and letters were better recalled when learned by writing rather than by looking only (Experiments 1 and 4). The advantage of writing was decreased, however, when the proper writing action prevented (i.e., when subjects were instructed to trace or write without feedback; Experiments 3 and 4) but not when the proper stroke orders were prevented (i.e., when subjects were instructed to write in reverse or random orders; Experiment 2). The results indicate that the writing action, rather than the use of stroke orders, is responsible for the effect.
\end{abstract}

In the logographic languages, such as Japanese and Chinese, the number of letters and characters to be learned is quite large. For example, Japanese children are required to learn almost 1,000 Chinese characters, in addition to 142 syllabary letters, during the 6 years of primary school. A traditional and assumedly effective way of learning letters and characters is repeated (hand)writing, in which one writes down to-be-remembered items over and over until one remembers them by heart (Kusumi, 1992; Mann, 1985; Onose, 1988; Sasaki, 1987; Takahashi \& Shimizu, 1989).

Onose $(1987,1988)$ showed that Hiragana (syllabary) and Chinese characters were learned more accurately by Japanese kindergarten and first grade children when the children were instructed to practice them by writing (copying) than when they practiced by tracing. Also, Naka and Naoi (1995) showed that graphic materials, but not verbal materials such as words and nonwords, were better recalled by Japanese and American undergraduate subjects when they learned by writing than when they learned by reading (looking). ${ }^{1}$ These results are in line with previous studies in educational psychology that showed that writing (copying) alphabetic letters brings a better outcome than tracing or looking only (for reviews, see Askov, Otto, \& Askov, 1970; Graham \& Weintraub, 1996; Peck, Askov, \& Fairchild, 1980). However, most of the

I thank the teachers and pupils of Tsuga, Masaki, Toyonari, Miyanogi, and Mitsuwadai-Minami Elementary Schools. Also, I am grateful to K. Ubukoshi and A. Watanabe for their help in the collection of data and to G. R. Loftus and the reviewers for valuable comments on the earlier version of the manuscript. Requests for reprints should be sent to M. Naka, Department of Educational Psychology, Chiba University, Chiba-shi, Chiba-ken, Japan, 263 (e-mail: mnaka@orion.e. chiba-u.ac.jp).

—Accepted by previous editor, Geoffrey R. Loftus subjects in these studies are preschoolers or first or second grade children who have just started learning letters, and it seems that no systematic research has been done to determine whether repeated writing facilitates children's learning of letters and characters over primary school years, during which Japanese children build up their basic vocabulary of Chinese characters. The purpose of this study is to determine whether repeated writing facilitates children's memory for letters and characters, as well as to investigate what aspect of writing is responsible for the effect.

Two aspects of writing processes that are distinguished in the models of writing ${ }^{2}$ (Ellis, 1982; Friedman \& Alexander, 1989; Margolin, 1984; Roeltgen \& Heilman, 1985; Thomassen \& Teulings, 1983) may be relevant to the effect of repeated writing. The first one is the use of stroke orders, which specify the directionality and sequence of strokes (Margolin, 1984). A conventional sequencing strategy for a particular graphic pattern is said to give it a economical structure (Van Sommer, 1984). Also, applying a familiar stroke order to a novel pattern is said to help one to organize it as a meaningful structure (Goodnow, 1977). A certain structure, given by writing with a conventional stroke order, may lead to better memory for the pattern than does only looking. If this is true, preventing the subjects from using the conventional stroke orders by instructing them to write in reverse or random directions would decrease the effect of repeated writing.

The second aspect of writing is writing action itselfthat is, the process wherein one pays attention to the tobe-written item, generates and holds the image, executes the motor program to reproduce the image, and then receives a visual feedback from the written item (Søvik, 1981; Thomassen \& Teulings, 1983). Such a process may yield a rich memory trace, as compared with only looking. If this is true, depriving the subjects of the usual writ- 
ing action by instructing them to trace or write without feedback would decrease the effect of repeated writing.

In this study, we first examined whether the effect of repeated writing was observed for primary school children (Experiment 1). Then we investigated whether the use of stroke orders (Experiment 2) and/or writing action (Experiment 3 ) had anything to do with the effect. These experiments were run with Chinese character-like items, which were new to the subjects but still might afford the use of the stroke orders for Chinese characters. In Experiment 4 , we studied the effect of repeated writing with the use of unfamiliar materials - that is, Arabic letters to which it would be difficult to apply the stroke orders.

\section{EXPERIMENT 1}

The purpose of this experiment was to see whether repeated writing, as compared with looking, better facilitates children's memory for the graphic items.

\section{Method}

Design. A grade (first, third, or fifth) $\times$ learning condition (writing or looking) experimental design was applied. Both factors were between-subjects.

Subjects. Two classes of first, third, and fifth grade children (six classes in all), from Masaki Elementary School in Togane City, Chiba Prefecture, participated in the study. Each class of each grade was assigned to one of two conditions, writing or looking. Table 1 shows details on the subjects.

Materials. Nine Chinese character-like items, each composed of five or six strokes, were chosen from a pool of graphic designs and used as to-be-remembered items (see the Appendix for examples). An A4 size booklet was made that consisted of a page for instruc- tions, five pages for learning to-be-remembered items, a page for an intervening task of calculation (addition and subtraction), and a page for a free recall test in which subjects were to write down the items that they could remember. Nine items on a page were arranged in three columns and three rows. Each item was printed in a $1.5 \times$ $2 \mathrm{~cm}$ scale. For the writing condition, a $2.7 \times 3.3 \mathrm{~cm}$ rectangular blank space was provided next to each item, in which the subjects were to be instructed to write down the item. The location of each item was changed for every page and subject in order to prevent a serial order effect.

Procedure. Each condition was tested in group in a classroom context. After a brief introduction, an experimenter (the author) read aloud the instructions on the first page: "You will see foreign characters in this booklet. Try to remember them by writing [by looking and marking]." The subjects in the looking condition were instructed to mark each item with a circle, so that they would pay enough attention to the material. All the subjects were instructed to write/look at an item at a fixed pace, so as to control the rehearsal intervals. Because a pilot study showed that first graders took longer to write down each item than did third and fifth graders, the interval was fixed to be $10 \mathrm{sec}$ per item for the first graders and $8 \mathrm{sec}$ per item for the third and fifth graders. The intervals for the writing and looking conditions were the same within a grade. The subjects were told to proceed to the next item when an oral sign, "Hai [next]," was given by the experimenter. The use of other strategies was prohibited.

The subjects were first given three exercise trials that used the shapes $(\Delta, I, H)$, and they then started writing/looking at the tobe-remembered items. Because there were five pages of items, the subjects wrote/looked at each of the nine items five times in all. They then were given an intervening task for $1 \mathrm{~min}$ to release the buffer memory, which was followed by a final free recall test. ${ }^{3}$ In the free recall test, the subjects were instructed to write down as many items as they could remember. Besides the experimenter, a research assistant and a classroom teacher attended the testing to help the subjects understand the procedures, as well as to encourage them to follow the instructions.

Table 1

The Number of Subjects and Their Ages in Experiments 1, 2, 3, and 4

\begin{tabular}{|c|c|c|c|c|c|c|c|c|c|}
\hline \multirow[b]{3}{*}{ Conditions } & \multicolumn{3}{|c|}{ First Grade } & \multicolumn{3}{|c|}{ Third Grade } & \multicolumn{3}{|c|}{ Fifth Grade } \\
\hline & \multicolumn{2}{|c|}{ No. } & \multirow{2}{*}{$\begin{array}{l}\text { Mean Age } \\
\text { (Range) }\end{array}$} & \multicolumn{2}{|c|}{ No. } & \multirow{2}{*}{$\begin{array}{l}\text { Mean Age } \\
\text { (Range) }\end{array}$} & \multicolumn{2}{|c|}{ No. } & \multirow{2}{*}{$\begin{array}{c}\text { Mean Age } \\
\text { (Range) }\end{array}$} \\
\hline & $\mathrm{B}$ & $\mathrm{G}$ & & $\mathrm{B}$ & $\mathrm{G}$ & & B & G & \\
\hline \multicolumn{10}{|l|}{ Experiment 1} \\
\hline Writing & 18 & 16 & $\begin{array}{c}7.4 \\
(7.0-7.10)\end{array}$ & 19 & 18 & $\begin{array}{c}9.4 \\
(8.11-9.10)\end{array}$ & 21 & 18 & $\begin{array}{c}11.5 \\
(10.11-11.10)\end{array}$ \\
\hline Looking & 15 & 17 & $\begin{array}{c}7.4 \\
(6.11-7.11)\end{array}$ & 20 & 19 & $\begin{array}{c}9.4 \\
(8.11-9.10)\end{array}$ & 21 & 18 & $\begin{array}{c}11.3 \\
(10.11-11.10)\end{array}$ \\
\hline \multicolumn{10}{|l|}{ Experiment 2} \\
\hline Writing orders & 14 & 16 & $\begin{array}{c}7.4 \\
(6.10-7.10)\end{array}$ & 16 & 14 & $\begin{array}{c}9.4 \\
(8.11-9.10)\end{array}$ & 16 & 11 & $\begin{array}{c}11.3 \\
(10.10-11.10)\end{array}$ \\
\hline \multicolumn{10}{|l|}{ Experiment 3} \\
\hline Tracing & 14 & 17 & $\begin{array}{c}7.4 \\
(6.11-7.10)\end{array}$ & 18 & 12 & $\begin{array}{c}9.4 \\
(8.11-9.10)\end{array}$ & 15 & 12 & $\begin{array}{c}11.3 \\
(10.11-11.10)\end{array}$ \\
\hline No-Feedback & 12 & 17 & $\begin{array}{c}7.4 \\
(6.11-7.10)\end{array}$ & 16 & 14 & $\begin{array}{c}9.4 \\
(9.0-9.10)\end{array}$ & 16 & 12 & $\begin{array}{c}11.4 \\
(11.0-11.10)\end{array}$ \\
\hline \multicolumn{10}{|l|}{ Experiment 4} \\
\hline Writing & 15 & 15 & $\begin{array}{c}7.4 \\
(6.11-7.10)\end{array}$ & 11 & 16 & $\begin{array}{c}9.3 \\
(8.11-9.10)\end{array}$ & 21 & 18 & $\begin{array}{c}11.3 \\
(10.11-11.9)\end{array}$ \\
\hline Looking & 17 & 15 & $\begin{array}{c}7.4 \\
(6.11-7.10)\end{array}$ & 15 & 15 & $\begin{array}{c}9.4 \\
(8.11-9.10)\end{array}$ & 19 & 19 & $\begin{array}{c}11.4 \\
(10.11-11.10)\end{array}$ \\
\hline Tracing & 14 & 13 & $\begin{array}{c}7.3 \\
(6.11-7.10) \\
\end{array}$ & 13 & 16 & $\begin{array}{c}9.4 \\
(8.11-9.9) \\
\end{array}$ & 15 & 15 & $\begin{array}{c}11.4 \\
(10.11-11.10)\end{array}$ \\
\hline
\end{tabular}

Note- $B$ and $G$ indicate the numbers of boys and girls. 


\section{Results and Discussion}

One subject's data were discarded because he did not complete the task. For the remainder of the subjects, correct responses in free recall were counted. A reproduction was judged to be correct if it had all the components but no more than the original had. ${ }^{4}$ The judgment was done by a trained assistant. Figure 1 shows the number of correct recalls with error bars, which indicate $95 \%$ confidence intervals. ${ }^{5}$ As is shown, the items were recalled better when learned by writing rather than by looking, although the difference was greater for the young subjects than for the older subjects.

\section{EXPERIMENT 2}

If the effect of repeated writing depended on the use of conventional stroke orders, its prevention would decrease the effect. In this experiment, we asked the subjects to learn items with three kinds of stroke orders: (1) The conventional order, which was determined on the basis of the conventional rules of writing Chinese characters (i.e., writing from top to bottom, left to right, outside to inside, and so on) and dominant stroke orders put down by undergraduates assessed beforehand; (2) the reverse order, which was the reverse of the conventional order; and (3) the random order, for which the sequence and directionality of each stroke was random. If the effect of writing depends on the use of the conventional stroke orders, we would expect the performance to be better for the conventional order condition than for the other conditions.

\section{Method}

Design. A grade (first, third, or fifth) $\times$ stroke order (conventional, reverse, or random) design was used. Because writing in reverse or random order is more difficult than writing in conventional order, we made the stroke order conditions within-subjects, so as to

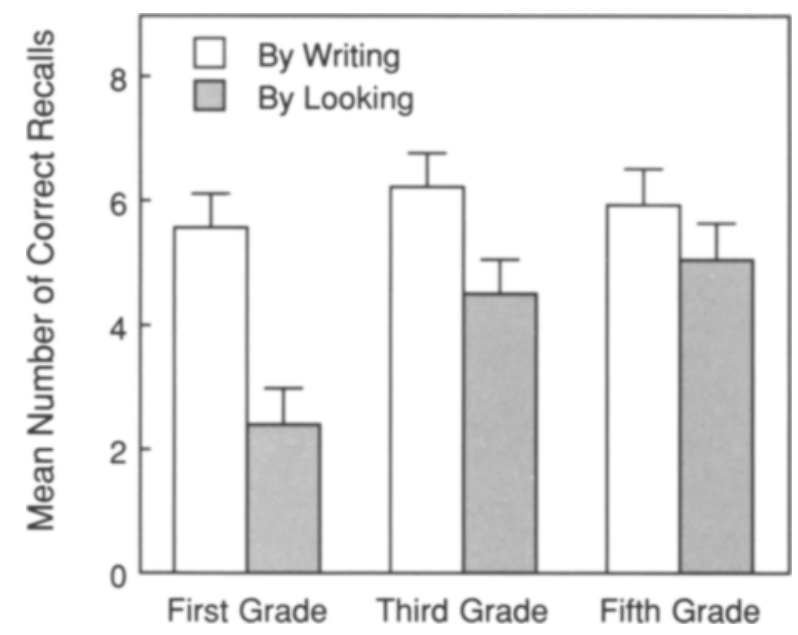

Figure 1. Results from Experiment 1: mean number of correct recalls for the writing and looking conditions. Error bars indicate $95 \%$ confidence intervals. avoid the situation in which subsets of subjects had to practice all the items with only the random or the reverse orders.

Subjects. New classes of first, third, and fifth grade children from Masaki Elementary School in Togane City, Chiba Prefecture, served as subjects. See Table 1 for details on the subjects.

Materials. The booklets were the same as those used for the writing condition in Experiment 1, except that the stroke orders were shown for each item by numbers and arrows. The conventional, the reverse, and the random stroke orders for each particular item were counterbalanced across subjects. More specifically, one third of the subjects learned three items (list A) by the conventional order, three others (list B) by the reverse order, and the rest (list C) by the random order. The next third of the subjects learned list $A$ by the reverse order, list $\mathrm{B}$ by the random order, and list $\mathrm{C}$ by the conventional order, and so on. Because the order conditions were within subjects, the range of to-be-remembered items for each condition was $0-3$.

Procedure. Instructions and procedures were the same as those in Experiment 1, except that the subjects were instructed to follow the stroke orders shown by the numbers and arrows. Because it was known from a pilot study that it took longer to write down an item following by instructed stroke orders, the interval for writing was extended to $60 \mathrm{sec}$ for the first graders and $30 \mathrm{sec}$ for the third and fifth graders for the first two pages of the materials. Thereafter, the interval was shortened to $30 \mathrm{sec}$ for the first graders and $12 \mathrm{sec}$ for the third and fifth graders. The intervals for the three order conditions were the same within a grade. This time, besides the experimenter, a classroom teacher and four assistants attended. If a subject tried to write an item with his or her own stroke orders, an assistant corrected the subject and encouraged him or her to follow the directed stroke orders. After they had written down the items, the subjects were given an intervening task and then a free recall test. The instruction for the free recall test was the same as that in Experiment 1: The subjects were asked to write down the items they could remember but were not required to write them in the learned stroke orders or to remember the stroke orders.

\section{Results and Discussion}

As in Experiment 1, the items were judged to be correct if they had all the components but no more than the originals had, no matter how they were written. As is presented in Figure 2, no effects of grades or stroke orders were observed.

\section{EXPERIMENT 3}

In this experiment, we studied whether the effect of repeated writing depended on the writing action itself, by comparing the writing condition in Experiment 1 with two more learning conditions, the tracing condition and the no-feedback condition. In the tracing condition, the subjects were instructed to trace items, whereas, in the no-feedback condition, they were instructed to write items with a pen in upside-down position, so that no trace was made. As was discussed before, if the writing action is described as the process wherein one pays attention to an original item, generates and holds the image, executes a motor program, and receives the visual feedback, then the tracing condition presumably would deprive subjects of generating and holding the image, because the item to be traced is always there and one would not have to generate or to hold its image. The no-feedback condition pre- 


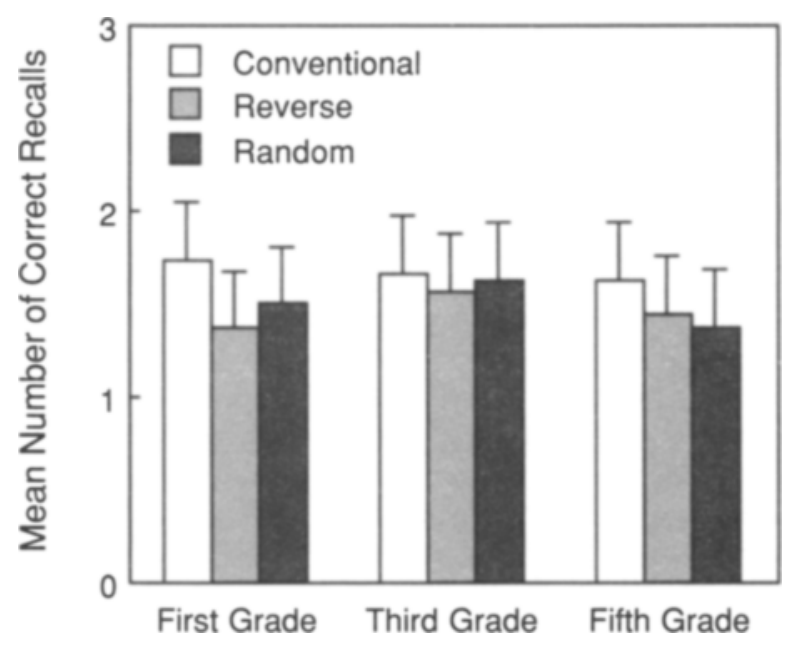

Figure 2. Results from Experiment 2: mean number of correct recalls for the conventional, reverse, and random order conditions.

sumably deprives subjects of receiving feedback. It was expected that the subjects' performances would decline in the tracing and no-feedback conditions.

\section{Method}

Design. A grade (first, third, or fifth) $\times$ learning condition (writing, tracing, or no-feedback) design was applied. Both factors were between-subjects.

Subjects. Two new classes of first, third, and fifth grade children (six classes in all) from Toyonari Elementary School in Togane City, Chiba Prefecture, participated. Each class of each grade was assigned to either the tracing condition or the no-feedback condition. See Table 1 for details on the subjects.

Materials. The booklets were the same as those used in Experiment 1 . For the tracing condition, the one without blank spaces (the one for the looking condition) was used. For the no-feedback condition, the one with blank spaces (the one for the writing condition) was used.

Procedure. Instructions and procedures were the same as those in Experiment 1 except that the subjects in the tracing condition were instructed to trace items, whereas the subjects in the no-feedback condition were instructed to write items in the blank spaces with the wrong end of a pen, so that no mark was made. In the latter condition, the subjects were carefully instructed not to leave any visible traces on the paper. The rehearsal interval was the same as that in Experiment 1 . The experimenter, an assistant, and a classroom teacher helped the subjects to understand the procedures and encouraged them to follow the instructions. After the practice, the intervening task and free recall test were given.

\section{Results and Discussion}

The results shown in Figure 3 support the prediction that prevention of the usual writing action would reduce the effect of repeated writing. In particular, the poor performance in the tracing condition corresponds to the results in Onose (1987, 1988), in which Japanese letters and characters were learned less accurately by tracing than by writing (copying). He speculated that the images needed in writing played an important role. Also, Levin, Ghatala, DeRose, and Makoid (1977) and Levin, Ghatala, De-
Rose, Wilder, and Norton (1975) reported that the subjects in an incidental discrimination learning task for pictures performed better when they traced the image of the picture from memory than when they traced directly on top of the picture. Images may play an important role in encoding graphic items.

\section{EXPERIMENT 4}

If memory for graphic items is facilitated by the writing action itself, rather than by the use of stroke orders, the effect will be observed even for unfamiliar materials to which the stroke orders for Chinese characters are difficult to apply. In the final experiment, we reexamined the effect of writing and its deprivation by comparing the writing condition with the looking and tracing conditions, using Arabic letters. ${ }^{6}$

A procedural modification was made in this experiment. In Experiments 1 and 3, the rehearsal interval per item was $10 \mathrm{sec}$ for the first graders and $8 \mathrm{sec}$ for the third and fifth graders, because older subjects write items faster than do younger subjects. Although the difference in timing would not jeopardize the comparisons between conditions within each grade (e.g., the comparison between the writing and the looking conditions within the first graders), one may feel it unfair to compare the conditions between grades (e.g., the comparison of writing conditions between the first and the third graders), because the first graders are said to have an advantage in terms of the rehearsal interval. In this experiment the rehearsal interval was set to be the same for all the subjects.

\section{Method}

Design. A grade (first, third, or fifth) $\times$ learning condition (writing, reading, or tracing) experimental design was applied. Both factors were between-subjects.

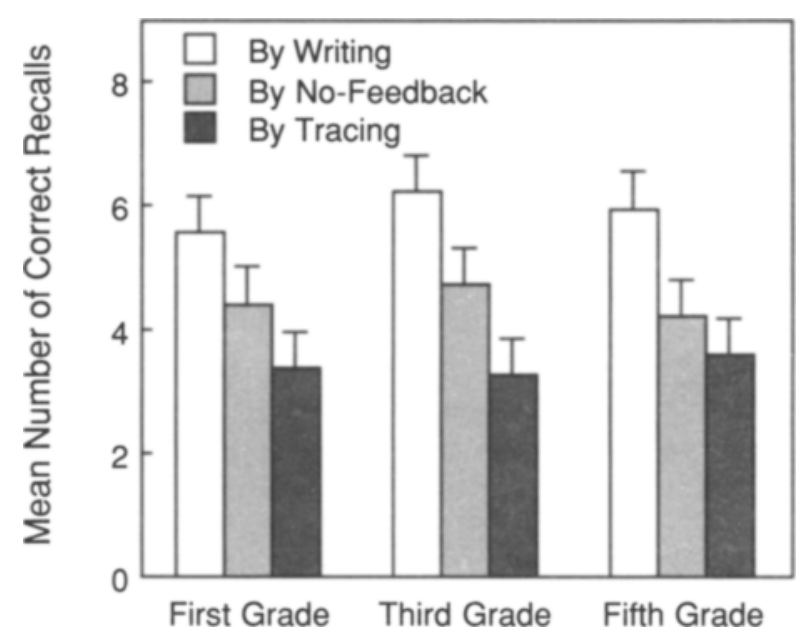

Figure 3. Results from Experiment 3: mean number of correct recalls for the tracing and the no-feedback conditions compared with the results of the writing condition in Experiment 1. 


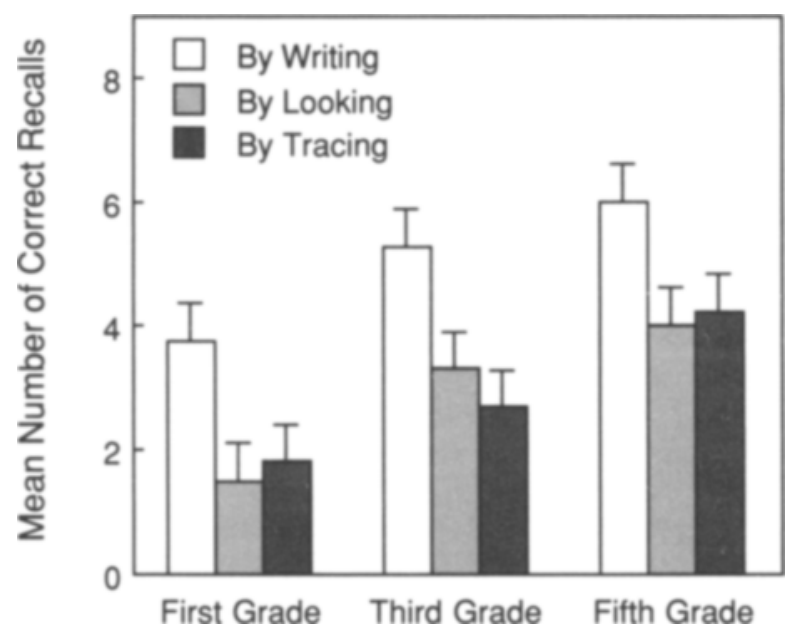

Figure 4. Results from Experiment 4: mean number of correct recalls for the writing, looking, and tracing conditions.

Subjects. Three new classes of first, third, and fifth grade children (nine classes in all) from Miyanogi and Mitsuwadai-Minami Elementary School in Chiba City, Chiba Prefecture, participated. One class of each grade was assigned to a different condition. See Table 1 for details on the subjects.

Materials. The booklets were the same as those used for the writing, looking, and tracing conditions in Experiments 1 and 3, except that Arabic letters were used (see the Appendix for examples).

Procedure. Instructions and procedures were the same as those in Experiments 1 and 3, except that the interval per item was set to be $10 \mathrm{sec}$ for the first two pages and then $8 \mathrm{sec}$ thereafter for all the subjects. The experimenter, an assistant, and a classroom teacher were present to help subjects understand the procedures, when needed.

\section{Results and Discussion}

The results are shown in Figure 4. The effect of repeated writing was replicated even for Arabic letters, to which it would have been difficult to apply the stroke orders for Chinese characters. Also, it was replicated that the performance was better for writing than for tracing, which indicates that the effect of repeated writing is associated with the writing actions.

It is worth noting that, in Experiment 1, the advantage of writing over looking was smaller for the older subjects than for the young subjects, whereas, in this experiment, the advantage was as great for the older subjects as for the young subjects. ${ }^{7}$ In Experiment 1, the familiarity of materials - that is, Chinese character-like items-might have facilitated the performance in the looking condition, especially for the older subjects, who had acquired a sufficient vocabulary of Chinese characters. On the other hand, in this experiment, in which the materials were new even to the older subjects, the performance in the looking condition might have not caught up with that in the writing condition.

\section{GENERAL DISCUSSION}

The present study was concerned with whether repeated writing facilitates children's memory for graphic items, such as pseudologographic characters and foreign letters, as well as with exploring which aspect of writing - the use of stroke orders or the writing action itself-is more responsible for the effect. It was found that the graphic items were better recalled when children learned them by writing rather than by looking (Experiment 1), replicating the results obtained from undergraduate subjects in Naka and Naoi (1995). It was also found that preventing the subjects from using a proper writing action - that is, tracing and writing without feedback - decreased the effect of repeated writing (Experiments 3 and 4), whereas preventing them from using a proper stroke order did not (Experiment 2). Furthermore, the results from Experiments 1 and 3 were replicated for Arabic letters, to which application of the stroke orders for Chinese characters would have been difficult. All in all, these results indicate that the writing action itself, rather than the use of stroke orders, is responsible for the effect of repeated writing.

The effect of repeated writing may be related to the effect of subject-performed tasks, the generation effect, effort, and/or interest. We must admit that, at this stage of study, we cannot determine which theory explains the effect best. However, the results at least showed that the motor movements required in tracing or the use of stroke orders were not sufficient to facilitate memory for letters and pseudocharacters, and our conjecture is that holding an image of the item during writing is important, as also was suggested in Onose $(1987,1988)$ and Levin et al. (1977; Levin et al., 1975). This conjecture needs to be studied further.

\section{REFERENCES}

Askov, E., Oтto, W., \& Askov, W. (1970). A decade of research in handwriting: Progress and prospect. Journal of Educational Research, 64, 100-111.

ElLIS, A. W. (1982). Spelling and writing (and reading and speaking). In A. W. Ellis (Ed.), Normality and pathology in cognitive functions (pp. 113-146). London: Academic Press.

FrIEDMAN, R. B., \& ALEXANDER, M. P. (1989). Written spelling Agraphia Brain \& Language, 36, 503-517.

Goodnow, J. (1977). Children's drawing. Fontana, CA: Open Books

Graham, S., \& Weintraub, N. (1996). A review of handwriting research: Progress and prospects from 1980 to 1994. Educational Psychology Review, 8, 7-87.

KusumI, T. (1992). Metakioku. [Meta-memory.] In Y. Anzai, S. Ishizaki, Y. Otsu, Y. Hatano, \& H. Mizoguchi (Eds.), Ninchikagaku handobukku [Handbook of cognitive science] (pp. 238-250). Tokyo: Kyoritsu Shuppan.

Levin, J. R., Ghatala, E. S., DeRose, T. M., \& Makoid, L. A. (1977) Image tracing: An analysis of its effectiveness in children's pictorial discrimination learning. Journal of Experimental Child Psychology, 23, 78-83.

Levin, J. R., Ghatala, E. S., DeRose, T. M., Wilder, L., \& Norton, R. W. (1975). A further comparison of imagery and vocalization strategies in children's discrimination learning. Journal of Educational Psychology, 67, 141-145.

Mann, V. A. (1985). A cross-linguistic perspective on the relation between temporary memory skills and early reading ability. Remedial \& Special Education, 6, 37-42.

MaRGolin, D. I. (1984). The neuropsychology of writing and spelling Semantic, phonological, motor, and perceptual processes. Quarterly Journal of Experimental Psychology, 36, 459-489.

NAKA, M., \& NaOI, H. (1995). The effect of repeated writing on memory Memory \& Cognition, 23, 201-212. 
ONOSE, M. (1987). The effect of tracing and copying practice on handwriting skills of Japanese letters in preschool and first grade children. Japanese Journal of Educational Psychology, 35, 9-16.

ONOSE, M. (1988). Effect of the combination of tracing and copying practices on handwriting skills of Japanese letters in preschool and first grade children. Japanese Journal of Educational Psychology, 36, 129-134.

PECK, M., AsKov, E. N., \& FaIRCHILD, S. H. (1980). Another decade of research in handwriting: Progress and prospect in the 1970s. Journal of Educational Research, 74, 283-298.

Roeltgen, D. P., \& Heilman, K. M. (1985). Review of agraphia and a proposal for an anatomically-based neuropsychological model of writing. Applied Psycholinguistics, 6, 205-230.

SASAKI, M. (1987). Why do Japanese write characters in space? International Journal of Behavioral Development, 10, 135-149.

SøviK, N. (1981). An experimental study of individualized learning instruction in copying, tracking, and handwriting based on feedback principles. Perceptual \& Motor Skills, 53, 195-215.

TAKAHASHI, M., \& ShIMIZU, H. (1989). Kyoshitsu bamen ni okeru jido no kanji gakushu ni oyobosu shoki rihasaru ryo no kouka to metaninchiteki handan. [The effect of rehearsal by writing and metacognition on children's learning of Chinese characters in the classroom.] Kansai Shinri Gakkai, 101, 55.

Thomassen, A. J. W. M., \& Teulings, H. H. M. (1983). The development of handwriting. In M. Martlew (Ed.), The psychology of written language: Developmental and educational perspectives (pp. 179 213). Chichester, U.K.: Wiley.

VAN Sommer, P. (1984). Drawing and cognition. Cambridge University Press.

\section{NOTES}

1. The exact Japanese word for this condition was miru, which means both reading and looking. In this paper, we translated miru as looking.

2. Labels for these aspects are different, depending on researchersfor example, graphic motor pattern buffer and neuro-muscular execution by Ellis (1982), graphic motor pattern and graphic code by Margolin (1984) and Friedman and Alexander (1989), graphic output programming and motor programming by Roeltgen and Heilman (1985). Following Thomassen and Teulings (1983), we refer to them as a process associated with the use of stroke orders and writing action itself.

3 . In the experiments reported in this study, only written free recall test was used as a measure, because the advantage of repeated writing over looking was expected only for free recall but not for recognition (Naka \& Naoi, 1995).
4. An item with the omission and/or addition of component(s) was counted as an error. In general, the number of errors showed a pattern of results similar to that for the effects of grades and learning conditionsthat is, errors decreased as the grade level increased (Experiments 1, 2, 3 , and 4) and more errors occurred in the looking and tracing conditions than in the writing and no-feedback conditions (Experiments 1, 3, and 4). Therefore, for brevity, these results were not included in the paper.

5 . The error bars for the following experiments also indicate $95 \%$ confidence intervals. Because there was no sex difference in this experiment, as well as in the following experiments, data from boys and girls were pooled together for analysis.

6. The no-feedback condition was not included because (1) the purpose of Experiment 4 was to see the effect of repeated writing with Arabic materials using modified procedures (intervals), which did not necessarily require the inclusion of no-feedback condition, and (2) it was difficult to monitor whether children properly wrote the unfamiliar Arabic letters containing curves and dots when no feedback was given.

7. An analysis of variance conducted for only the writing condition in Experiment 1 resulted in no difference between grade levels $[F(2,107)=1.46, p=.23$; means were $5.5,6.2$, and 5.9 for first, third, and fifth graders], whereas, in Experiment 4, it resulted in a significant difference between the grade levels $[F(2,93)=14.17, p<.0001$; means were 3.7, 5.2, and 6.0 for first, third, and fifth graders].

\section{APPENDIX}

Examples of the material used in Experiments 1 to 3.

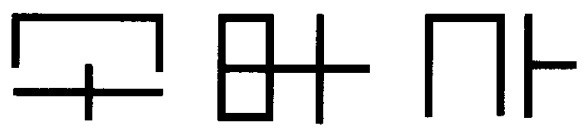

Examples of the material used in Experiment 4.

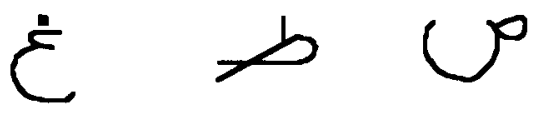

(Manuscript received December 24, 1996; revision accepted for publication May 8, 1997.) 